\title{
REFLEXIVITY OF A BANACH SPACE WITH A UNIFORMLY NORMAL STRUCTURE
}

\author{
JONG SOOK BAE
}

\begin{abstract}
In this note we prove that any Banach space with a uniformly normal structure is reflexive.
\end{abstract}

1. Introduction. In [4] Gillespie and Williams gave the concept of uniformly normal structure of Banach spaces. They showed that any nonexpansive self-map of a closed convex bounded subset of a Banach space with a uniformly normal structure has a fixed point, and, in [5], obtained the same result for the Kannan-type maps.

In this note, we show that any Banach space with a uniformly normal structure is reflexive, and, consequently, the main results of Gillespie and Williams are actually contained in those of Kirk [9], Godhe [6] and Kannan [8], respectively.

2. Main result. A Banach space $X$ is said to have a uniformly normal structure if there exists a number $h, 0<h<1$, such that if $C$ is a closed convex bounded subset of $X$, then there exists $x$ in $C$ such that $\sup \{\|x-y\| ; y \in C\} \leqslant h \delta(C)$, where $\delta(C)$ denotes the diameter of the set $C$.

To prove our theorem, we adopt the idea of Huff [7].

THEOREM. Any Banach space with a uniformly normal structure is reflexive.

Proof. We use a theorem of Eberlein and Smulian [2, p. 51]. Let $\left\{K_{n}\right\}$ be a decreasing sequence of nonvoid closed convex bounded subsets of a given Banach space with a uniformly normal structure. We need to show that $\cap K_{n} \neq \varnothing$. For each $n$, choose $x_{n} \in K_{n}$. Call a sequence $\left\{y_{n}\right\}$ a $c$-subsequence of $\left\{x_{n}\right\}$ provided there exists a sequence of integers $1=p_{1} \leqslant q_{1}<p_{2} \leqslant q_{2}<\cdots$ and coefficients $\alpha_{i} \geqslant 0$ such that, for each $n$,

$$
\sum_{i=p_{n}}^{q_{n}} \alpha_{i}=1, \quad y_{n}=\sum_{i=p_{n}}^{q_{n}} \alpha_{i} x_{i} .
$$

Then for each $\varepsilon>0$, there exists a $c$-subsequence $\left\{y_{n}\right\}$ of $\left\{x_{n}\right\}$ with $\left\|y_{n}-y_{m}\right\|<\varepsilon$ for each $n, m$. Suppose this is not true for some $\varepsilon>0$.

Let $L_{m}=\left\{x_{n}\right\}_{n=m}^{\infty}$. Let $\operatorname{co}\left(L_{m}\right)$ and $\overline{\operatorname{co}}\left(L_{m}\right)$ denote the convex hull and the closed convex hull of $L_{m}$, respectively. Then there exists $h, 0<h<1$, and $y_{1}^{\prime} \in \overline{\operatorname{co}}\left(L_{1}\right)$ such

Received by the editors April 15, 1983 and, in revised form, June 24, 1983.

1980 Mathematics Subject Classification. Primary 46B20; Secondary 47H10.

Key words and phrases. Uniformly normal structures, reflexive Banach spaces.

(C)1984 American Mathematical Society $0002-9939 / 84 \$ 1.00+\$ .25$ per page 
that $\sup \left\{\left\|y_{1}^{\prime}-y\right\| ; y \in \overline{\operatorname{co}}\left(L_{1}\right)\right\} \leqslant h \delta\left(L_{1}\right)$. Let $0<h<h_{1}<1$. Then by the triangle inequality there exists $y_{1} \in \operatorname{co}\left(L_{1}\right)$ such that $\sup \left\{\left\|y_{1}-y\right\| ; y \in \overline{\operatorname{co}}\left(L_{1}\right)\right\} \leqslant h_{1} \delta\left(L_{1}\right)$. Since $y_{1}$ is a finite linear combination of members in $L_{1}$, there exists a $c$-subsequence $\left\{y_{n}\right\}$ of $\left\{x_{n}\right\}$ such that $\sup \left\{\left\|y_{n}-y\right\| ; y \in \overline{\operatorname{co}}\left(L_{p_{n}}\right)\right\} \leqslant h_{1} \delta\left(L_{p_{n}}\right) \leqslant h_{1} \delta\left(L_{1}\right)$, and this inequality shows that $\delta\left(\left\{y_{n}\right\}\right) \leqslant h_{1} \delta\left(L_{1}\right)$. By repeating the argument, there exists a successive $c$-subsequence with diameter less than or equal to $h_{1}^{2} \delta\left(L_{1}\right)$. We need only repeat the argument a sufficient number $k$ of times with $h_{1}^{k} \delta\left(L_{1}\right)<\varepsilon$ to obtain a contradiction.

Next by the diagonal method, there exists a $c$-subsequence of $\left\{x_{n}\right\}$ which is norm Cauchy, and hence convergent to some $y$. Then $y \in \cap K_{n}$.

Remarks. Bynum [1] showed that a uniformly convex Banach space has a uniformly normal structure. But the converse is not true. For example, the space $l_{2}$, renormed by

$$
\left\|\left(x_{i}\right)\right\|_{1}=\max \left\{\left|x_{1}\right|,\left(\sum_{i=2}^{\infty}\left|x_{i}\right|^{2}\right)^{1 / 2}\right\}
$$

has a uniformly normal structure, but $\left(l_{2},\|\|_{1}\right)$ is not uniformly convex.

Bynum [1] also showed that there exists a reflexive space with normal structure, but without a uniformly normal structure.

\section{REFERENCES}

1. W. L. Bynum, Normal structure coefficients for Banach spaces, Pacific J. Math. 86 (1980), 427-435.

2. M. M. Day, Normed linear spaces, Springer-Verlag, New York and Berlin, 1973.

3. D. V. Dulst, Equivalent norms and the fixed point property for nonexpansive mappings, J. London Math. Soc. 25 (1982), 139-144.

4. A. A. Gillespie and B. B. Williams, Fixed point theorem for nonexpansive mappings on Banach spaces with uniformly normal structures, Applicable Anal. 9 (1979), 121-124.

5. Some theorems on fixed points in Lipschitz and Kannan-type mappings, J. Math. Anal. Appl. 74 (1980), 382-387.

6. D. Godhe, Zum prinzip der Kontraktiven Abbildung, Math. Nachr. 30 (1965), 251-258.

7. R. Huff, Banach spaces which are nearly uniformly convex, Rocky Mountain J. Math. 10 (1980), 743-749.

8. R. Kannan, Fixed point theorems in reflexive Banach spaces, Proc. Amer. Math. Soc. 38 (1973), $111-118$.

9. W. A. Kirk, A fixed point theorem for mappings which do not increase distances, Amer. Math. Monthly 72 (1965), 1004-1006.

Department of Mathematics, Chungnam National University, Daejeon, Seoul, Korea 